\title{
Joyce Mansour, Euvres complètes. Prose et poésie
}

\section{Tania Collani}

\section{(Q) OpenEdition}

\section{Journals}

\section{Edizione digitale}

URL: http://journals.openedition.org/studifrancesi/1446

DOI: 10.4000/studifrancesi. 1446

ISSN: 2427-5856

\section{Editore}

Rosenberg \& Sellier

\section{Edizione cartacea}

Data di pubblicazione: 1 décembre 2015

Paginazione: 627

ISSN: 0039-2944

\section{Notizia bibliografica digitale}

Tania Collani, «Joyce Mansour, EFuvres complètes. Prose et poésie», Studi Francesi [Online], 177 (LIX

III) | 2015, online dal 01 décembre 2015, consultato il 08 janvier 2021. URL: http://

journals.openedition.org/studifrancesi/1446 ; DOI: https://doi.org/10.4000/studifrancesi.1446

Questo documento è stato generato automaticamente il 8 janvier 2021.

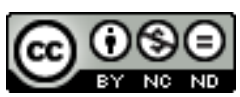

Studi Francesi è distribuita con Licenza Creative Commons Attribuzione - Non commerciale - Non opere derivate 4.0 Internazionale. 


\title{
Joyce Mansour, CEuvres complètes. Prose et poésie
}

\author{
Tania Collani
}

\section{NOTIZIA}

JOYCE MANSOUR, CEuvres complètes. Prose et poésie, préface de Paul LOMBARD, Parigi, Michel de Maule, 2014, pp. 640.

1 Tra il 2014 e il 2015, Joyce Mansour (1928-1986) riesce finalmente a occupare il posto che le spetta agli occhi della critica letteraria e artistica internazionale: una mostra è stata organizzata in suo onore al museo parigino del Quai Branly (Joyce Mansour, poétesse et collectionneuse, 18 novembre 2014-1 febbraio 2015); la sua biografia, che lega indissolubilmente la sua storia a quella di André Breton e del movimento surrealista, è pubblicata da Marie-Francine Mansour presso le edizioni France-Empire (Une Vie surréaliste, Joyce Mansour complice d'André Breton, 2014); e la riedizione delle sue opere complete (ormai introvabile nella prima edizione del 1991 di Actes Sud) è uscita grazie all'editore Michel de Maule nel 2014. Occorre felicitarsi per tali iniziative, perché l'opera di questa poetessa dalle tinte erotiche e scure sa imporsi al lettore odierno, così come aveva saputo ammaliare Breton, che le scriveva: «J'aime Madame, le parfum de l'orchidée noire - ultra-noire - de vos poèmes».

2 Il presente volume riprende dunque i testi contenuti nelle seicento pagine della prima edizione di Actes Sud, intitolata Prose \& Poésie. Vengono riprese le quattro opere in prosa: Les Gisants satisfaits (1958), Jules César (1958), Ça (1970) e Histoires nocives (1973); una pièce teatrale, Le Bleu des fonds (1968); e sedici raccolte di poesia, da Cris (1953) a Trous noirs (1986), senza dimenticare la serie di poesie postume o pubblicate in riviste e cataloghi.

3 L'istinto da poeta che caratterizza la scrittura di Joyce Mansour emana fin nella sua prosa. I suoi maestri e ispiratori sono Sade, Lautréamont, Bataille, senza trascurare l'impronta lasciata da Artaud. Il suo senso dell'immagine, la sua cultura artistica e la 
forza delle sue metafore sono legate al gruppo surrealista, che frequenta attivamente a Parigi a partire dagli anni Cinquanta. Nell'antologia curata da Penelope Rosemont, Surrealist Women (Londra, The Athlone Press, 1998, p. 203), veniva già descritta come uno dei tre poeti francofoni più importanti per il surrealismo nel secondo dopoguerra: «With her deep-sea insolence, mountain-high erotic rage, and bitter, insect-leggy laughter, Joyce Mansour gave the world an astonishing body of poetry such that no woman had ever written».

4 Nata da un'agiata famiglia britannica coloniale in Egitto, Mansour arriva alla lingua francese in seguito al suo secondo matrimonio con Samir Mansour, nel 1949. Il suo rapporto con il francese, come scrive Paul Lombard nella sua breve prefazione al volume, è quello di una sradicata, di un'esiliata, passata attraverso prove identitarie che lasciano una traccia palpabile nella sua opera (la morte della madre quando aveva quindici anni e del primo marito quando ne aveva diciannove, in entrambi i casi per cancro): «Chez elle, la virginité de son français traduit l'urgence de ses messages» (p. 9). L'ultimo racconto de Les Gisants satisfaits s'intitola per l'appunto «Le Cancer», e ripercorre in chiave fittizia la sua vicenda biografica, segnando in qualche modo la consapevolezza della sua condanna all'urlo e alla violenza: «Les journaux déclarèrent que ma maîtresse était morte d'un cancer; personne ne s'occupa de moi malgré la déposition peu favorable de Satan; la maison fut vendue, la bosse enterrée. Depuis lors, je vis tranquillement avec ma douleur, ma langue enfin déliée et le petit crabe trouvé incompréhensiblement près du cadavre; certains jours j'ai l'impression qu'il me ressemble» (p. 84). 